\title{
Image-Enhanced Magnified and Capsule Endoscopic Characterization of Pseudomelanosis Duodeni
}

\author{
Vincent Zimmer ${ }^{\text {a, b }}$ Kai Emrich ${ }^{c}$ Siegfried Exner ${ }^{\mathrm{a}}$ \\ ${ }^{a}$ Department of Medicine, Marienhausklinik St. Josef Kohlhof, Neunkirchen, Germany; ${ }^{b}$ Department of \\ Medicine II, Saarland University Medical Center, Saarland University, Homburg, Germany; ' Institute of Pathology \\ Saarbrücken-Rastpfuhl, Saarbrücken, Germany
}

Keywords

Iron deficiency anemia · Endoscopy · Prussian blue stain · Duodenum

\section{Caracterização endoscópica de pseudomelanosis duodenal por endoscopia de ampliação e cápsula}

\section{Palavras Chave}

Anemia ferropénica · Endoscopia · Coloração azul da Prússia · Duodeno

An 84-year-old female was referred for exclusion of gastrointestinal bleeding for anemia workup (hemoglobin $8.1 \mathrm{~g} / \mathrm{dL}$; mean corpuscular volume $86 \mathrm{fL}$ ). With a view to clinical, laboratory and endoscopic findings, the latter was ex post considered to represent anemia of chronic disease with a putative renal component. Medical history included curatively treated breast cancer, diabetic chronic kidney disease (Dialysis Outcome Quality Initiative stage $3 \mathrm{~A}$ ) and rheumatoid arthritis. The patient was on multiple chronic medications including hydrochloro-

karger@karger.com www.karger.com/pjg

Karger"

BOPEN ACCESS (c) 2021 Sociedade Portuguesa de Gastrenterologia Published by S. Karger AG, Basel

This article is licensed under the Creative Commons AttributionNonCommercial-NoDerivatives 4.0 International License (CC BYNC-ND) (http://www.karger.com/Services/OpenAccessLicense). Usage and distribution for commercial purposes as well as any distribution of modified material requires written permission. quine, cholecalciferol, torasemide, letrozole, iron-(II)sulfate and a mixture of dissolved and isophane insulin. Of note, there was no recent intake of any nonsteroidal anti-inflammatory drugs.

The recent routine esophagogastroduodenoscopy was significant for a duodenal mucosa diffusely speckled by multiple tiny brownish-black spots (Fig. 1a). Image-enhanced magnification endoscopy of the duodenal surface indicated a well-preserved villous architecture with linked color imaging (Eluxeo, Fuji, Düsseldorf, Germany) highlighting brownish pigment in the villous tips [1] (Fig. 1b). Histopathology likewise demonstrated brown pigmented granules within macrophages with positive iron staining studies, replicating the endoscopic diagnosis of pseudomelanosis duodeni (Fig. 1c). An ancillary small-bowel capsule endoscopy (PillCam SB3, Medtronic, Meerbusch, Germany) could reproduce these findings to be limited to the duodenal mucosal lining, and, in concert with an unrevealing ileocolonoscopy, a potential gastrointestinal bleeding source was firmly excluded (Fig. 1d).

Pseudomelanosis duodeni is an incidental, yet engrammatic endoscopic finding with no known clinical relevance [2]. Albeit its distinct pathogenesis has to be better delineated, clinical associations exist as to chronic 
Fig. 1. a Routine esophagogastroduodenoscopy demonstrating a duodenal mucosa speckled by multiple tiny brownish to black spots in the descending duodenum. b Cap-fitted image-enhanced magnification endoscopy using linked color imaging indicated an intact villous architecture with brownish deposits in the villous tips. c Histopathology of duodenal biopsies indicated pigment within macrophages in the tip of the villi with iron stains confirming iron deposits (left: hematoxylin-eosin, $\times 20$; right: Prussian blue, $\times 20$ ). d Small-bowel capsule endoscopy replicated these findings and confirmed limitation to the duodenum, while excluding a potential smallbowel bleeding source.
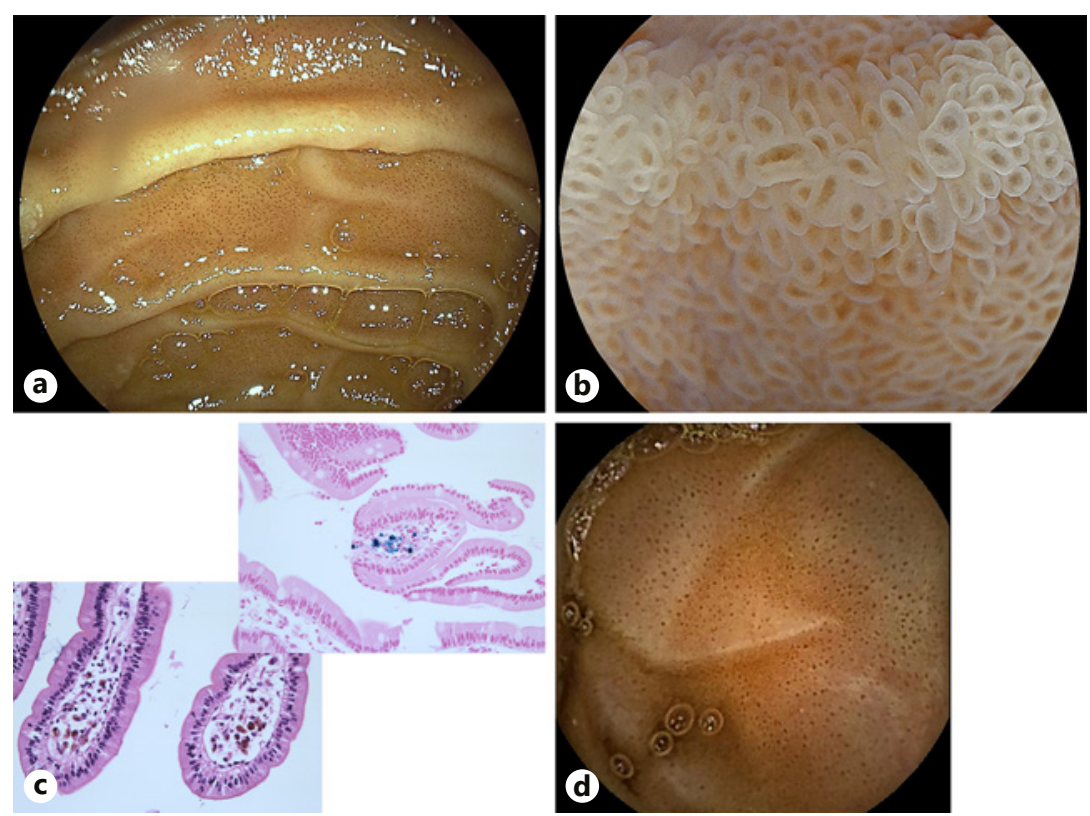

kidney disease and altered duodenal iron transport and sulfa moieties, included in certain mostly antihypertensive medications typically linked to it, such as hydralazine [3]. As is illustrated here, specialized high-quality endoscopy is instrumental in rapid identification and characterization of its engrammatic endoscopic features as well as forestalling the characteristic underlying histopathology.

\section{Statement of Ethics}

The patient has given written informed consent for publication (including publication of images).

\section{Conflict of Interest Statement}

The authors have no conflicts of interest to declare.

\section{Funding Sources}

No funding.

\section{Author Contributions}

V.Z.: clinical care, drafting and finalization of the paper; K.E.: pathology, revision and final approval of the paper; S.E.: clinical care, revision and final approval of the paper.

\section{References}

1 Tsai YN, Tsai JW, Tai CM. Education and imaging. Gastrointestinal: magnifying endoscopy for pseudomelanosis duodeni. J Gastroenterol Hepatol. 2016 Mar;31(3):520.

2 Giusto D, Jakate S. Pseudomelanosis duodeni: associated with multiple clinical conditions and unpredictable iron stainability - a case series. Endoscopy. 2008 Feb;40(2):165-7.

3 Almeida N, Figueiredo P, Lopes S, Freire P, Sousa V, Lérias C, et al. Small bowel pseudomelanosis and oral iron therapy. Dig Endosc. 2009 Apr;21(2):128-30. 